\title{
Patient Knowledge of Opioid Usage and Side Effects Prior to Surgery
}

\author{
Anthony Duncan", MD; Mitchell Alameddine ${ }^{\dagger}, \mathrm{MD}$; \\ Timothy Baerg ${ }^{\ddagger}, \mathrm{MD}, \mathrm{MBA}$; Nonie S. Arora ${ }^{\S}$, MD, MBA; \\ Hannah Cottrell", MD; Shaina Sekhri", MD; Alex Hallway ${ }^{\dagger \dagger}, \mathrm{BS}$; \\ Ryan Howard ${ }^{\ddagger \ddagger}, \mathrm{MD}$; Jennifer Waljee ${ }^{\S}, \mathrm{MD}, \mathrm{MS}$
}

\section{Background}

Given the increasing morbidity and mortality related to prescription opioids in the United States, it is critical for patients to understand the risks and proper usage of opioid analgesics.

\section{Methods}

We surveyed 166 patients undergoing elective surgery at a single tertiary care facility preoperatively. We queried patients regarding aspects of prescription opioid use, side effects and adverse effects, and storage and disposal behaviors.

\section{Results}

Overall knowledge regarding prescription opioids was high (mean score $=8.05 / 12$, range $0-12)$. The average number of questions answered correctly was not significantly different based on opioid use at the time of the survey ( $65 \%$ vs $67.5 \%, \mathrm{p}=0.52)$. Characteristics significantly associated with higher knowledge included young age $(p=0.01)$, female gender $(\mathrm{p}<0.01)$, and white race $(\mathrm{p}=0.01)$.

"University of North Dakota School of Medicine and Health Sciences, anthony.duncan@und.edu tUniversity of Michigan, malamedd@umich.edu

抽然ersity of Minnesota, tbaerg@umich.edu

§University of Michigan, aroranon@umich.edu

『New York-Presbyterian Hospital Weill Cornell Medicine, hannahrc@umich.edu

"Medical College of Wisconsin, ssekhri@umich.edu

(iD https://orcid.org/0000-0001-8691-9955

+†University of Michigan, ahallway@umich.edu

(D) https://orcid.org/0000-0003-1647-203X

\#University of Michigan, rhow@umich.edu

(D) https://orcid.org/0000-0001-9877-9603

§§University of Michigan, filip@med.umich.edu

doi: 10.3998/mjm.1436

Conflicts of interest:

The authors have no conflicts of interest to disclose 


\section{Conclusions}

Patient knowledge regarding prescription opioids is high preceding surgery, but gaps remain regarding side effects and adverse effects. Knowledge did not differ by prior or current opioid use, and these findings may help target important knowledge gaps to improve patient education regarding opioids during the preoperative period.

\section{Keywords \\ opioid $\bullet$ pre-operative $\bullet$ knowledge $\bullet$ opioid education}

\section{Introduction}

Although opioid analgesics are commonly used for postoperative pain control, the morbidity and mortality related to prescription opioid misuse, dependence, and abuse has increased in the United States. ${ }^{1-3}$ Opioids are one of the most commonly prescribed postoperative medications. ${ }^{4}$ Prescription opioids are commonly provided following surgical care for acute pain. However, the majority of pills remain unused, and prior research suggests that the majority of individuals do not dispose of these medications. ${ }^{5,6}$ It has been shown that the majority of non-medical opioid use arises from leftover opioids from family members, friends, or one's own prescription for opioids. ${ }^{7}$ Moreover, the initial use of opioids for non-medical purposes has a strong correlation with the initiation of illicit substance abuse, including heroin. ${ }^{8-10}$

In response, there has been increased focus on educating patients on the risks of opioid medications and their appropriate storage and disposal methods. ${ }^{11,12}$ Prior work has identified knowledge gaps in the use and storage of opioids in cancer outpatients, ${ }^{13}$ those with chronic pain, and in the emergency department. ${ }^{13,14}$ These studies demonstrate the high rate of improper use, storage, and disposal of opioids in these populations. Although opioid analgesics are often highly effective for acute pain, they are associated with important side effects, including respiratory depression, hyperalgesia, and dependence. ${ }^{15}$ Due to the potential for harm associated with these effects, it is important that patients are knowledgeable about the risks of taking these medications in the context of surgical care.

To date, the extent to which patients undergoing surgery are aware of the risks of opioids remains unclear. To understand this, we surveyed patients preparing for elective surgical procedures at a tertiary care center to determine their knowledge of prescription opioids. We specifically sought to understand differences in knowledge between groups of patients based on whether they were currently using opioids, patient age, and demographic characteristics. We hypothesized that patients currently on opioids would perform better on our survey regarding knowledge of opioid medications than patients not on opioids prior to surgery given their prior exposure and experience. We further hypothesized that knowledge differences will be present based on age regarding these medications given the increased awareness of the opioid epidemic.

\section{Methods}

\section{Study Cohort}

We surveyed 177 adult patients in the preoperative clinic at the University of Michigan Health System (UMHS). We included patients who were ages 18 years and older undergoing one of 
the following 8 surgeries: laparoscopic or open cholecystectomy, laparoscopic or open incisional hernia repair, laparoscopic open abdominal hysterectomy, bariatric surgery, anti-reflux surgery, and colectomy. Patients were excluded if they did not complete the survey for every variable of interest $(\mathrm{n}=11)$, yielding a final analytic sample of 166 individuals.

\section{Data Collection}

Eligible patients were approached by a member of the research team at their preoperative clinic appointment. Patients were then consented and given the survey to complete on a tablet. The survey was conducted utilizing the online system Qualtrics.

\section{Patient Opioid Knowledge}

Question themes were taken from the Patient Opioid Education Measure (POEM), a survey of approximately 40 open-ended questions for individuals taking opioids for chronic, non-malignant pain. ${ }^{3}$ The POEM evaluates knowledge and expectations surrounding opioid use, including legal issues, prescribing policies, safe use and handling, expected outcomes, side effects, pharmacology, and warnings. A team of physicians and pain psychologists at the Michigan Opioid Prescribing Engagement Network selected appropriate themes from this measure applicable to the perioperative period. Chosen themes were transformed into a series of closed-ended questions, including 7 true or false questions, 3 yes or no questions, and 2 multiple choice questions. Patients were always given the choice to respond that they did not know the answer to a question. These knowledge questions focused on important side effects of opioids (respiratory depression, constipation, and addiction), warnings surrounding opioids (driving, alcohol, and activity restrictions and medications that require consultation with a physician before taking), and proper use and handling of opioids (not sharing medication and not using medication for reasons other than indicated). All survey items are detailed in Appendix 1. For the analysis, each patient was given a test score for which they received 1 point for every correct answer and 0 points for each incorrect answer. The number of correct responses were summed to create the outcome variable.

\section{Patient Factors}

Patients' race/ethnicity, highest completed level of education, and use of opioids at the time of the survey were self-reported, and their age and gender were obtained from their electronic medical record. Age was categorized as 18 to 34 years of age, 35 to 44 years of age, 45 to 54 years of age, 55 to 64 years of age, and 65 years of age and older. Gender, race/ethnicity, and opioid status were dichotomized: gender as male and female, race/ethnicity as white and non-white, and opioid status as current user and not a current user. Finally, highest level of completed education was divided into three categories: graduate school, college, and less than college.

\section{Statistical Analysis}

Multiple regression analysis was performed that included current opioid use, age, gender, race, and highest level of education as predictor variables. Difference in means analysis was performed to examine the relationship between the sum of patients' correct answers and their age, gender, race, ethnicity, highest completed level of education, and opioid use at the time of the survey. All analyses were conducted using SAS 9.4 (SAS Institute Inc). 


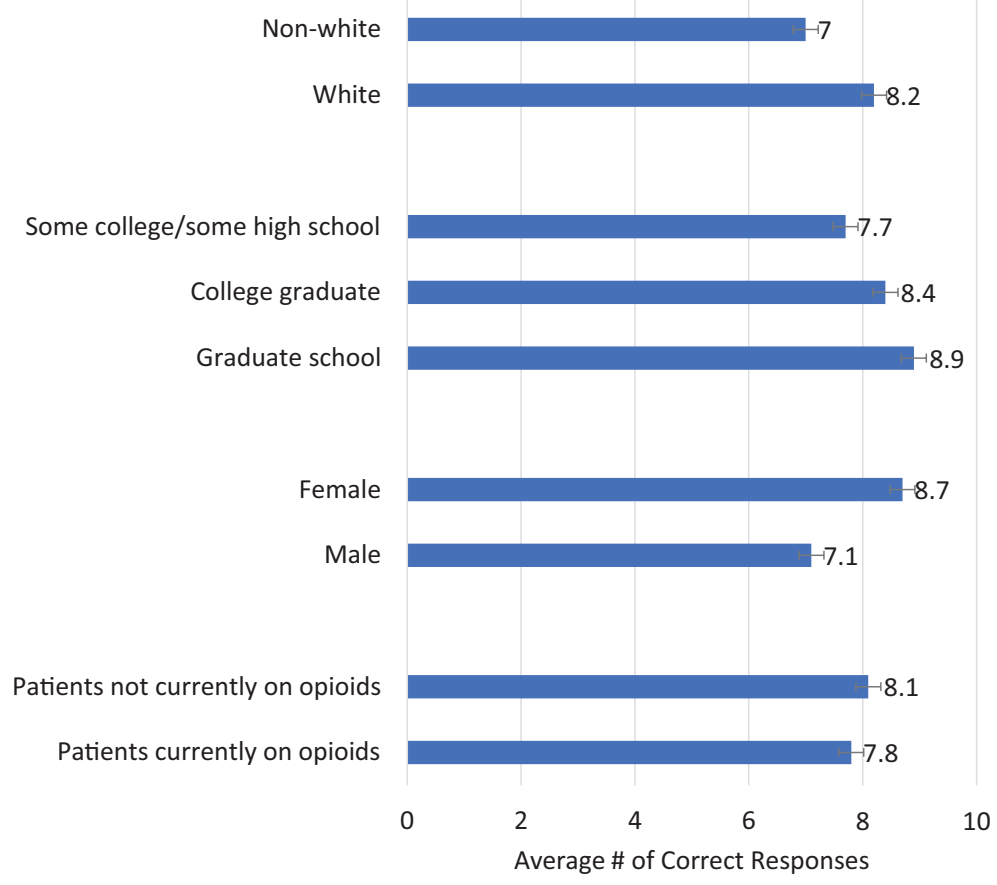

Figure 1. Average Score Versus Demographic Descriptors

Averaged scores per patient with a maximum score of 12 . Opioid naïve vs patients currently on opioids 7.8 vs 8.1 , p-value $=0.52$. Gender male compared to female 7.1 to $8.7 \mathrm{p}$-value $<0.001$. Education included graduate school, college, and some college/some high school with $8.9,8.4$, and 7.7 , respectively, $\mathrm{p}$-value 0.54 . White patients compared to non-white patients 8.2 vs 7.0 , p-value $<0.001$.

\section{Results}

\section{Study Cohort}

In this cohort of 166 patients, $18 \%$ of individuals reported they were currently using opioid medications. Males made up $42 \%$ of this sample, whereas females made up 58\%. The majority of participants reported their ethnicity as white (87\%) and that they were college educated $(67 \%)$. Demographic information is represented in Table 1.

Figure 1 illustrates the unadjusted average survey scores by patient characteristics, categories compared by t test. Interestingly, we observed that patients who were not currently taking opioids had similar scores to patients currently on opioids ( 7.8 vs $8.1 ; p=0.52$ ). Younger age was associated with higher overall scores compared with older patients $(p=0.011)$. Women had higher overall scores compared with male patients $(8.7$ vs $7.2, \mathrm{p}<0.001)$. White patients had higher overall scores compared with non-white patients ( 8.2 vs $7.0 ; p<0.001)$. We did not observe significant differences by highest level of education completed.

Figure 2 represents the mean number of correct answers broken down by the individual response, stratified by current opioid use. Four of the 12 questions had an average score of over 80\%; the remaining question averages all fell below 80\%. The question with the lowest correct response rate in both groups was about which medications the patient should consult a physician about before taking alongside an opioid. Less than $20 \%$ of patients answered this question correctly in both groups. Similar averages are seen among the groups with no significant difference in response between the two groups. 
Table 1. Demographic Characteristics of Study Cohort $(\mathrm{N}=166)$

\begin{tabular}{|l|c|}
\hline Category & $\mathbf{n}(\%)$ \\
\hline Current opioid user & $30(18.1)$ \\
\hline Yes & $136(81.9)$ \\
\hline No & \\
\hline Age & $18(10.8)$ \\
\hline 18 to 34 & $34(20.5)$ \\
\hline 35 to 44 & $30(18.1)$ \\
\hline 45 to 54 & $34(20.5)$ \\
\hline 55 to 64 & $50(30.1)$ \\
\hline 65 and older & \\
\hline Gender & $69(41.6)$ \\
\hline Male & $97(58.4)$ \\
\hline Female & \\
\hline Race & $145(87.3)$ \\
\hline White & $21(12.7)$ \\
\hline Non-white & $56(33.7)$ \\
\hline Education & $55(33.1)$ \\
\hline Graduate school & $55(33.1)$ \\
\hline College & \\
\hline$<$ College & \\
\hline
\end{tabular}

A multivariable analysis was conducted, which is represented in Table 2. A statistically significant difference of 1.37 was found with respect to race ( $\mathrm{CI}=-2.46$ to $-0.27 ; \mathrm{p}=0.015$ ). Higher scores were found in a younger patient with $\mathrm{p}$-value of 0.011 . When looking at gender, higher scores were found in female with a mean difference of $1.39(\mathrm{CI}=0.54$ to 2.06; $\mathrm{p}=0.001$ ). When looking at the current opioid users and opioid naïve scores, we found an insignificant difference of $0.30(-1.25$ to $-0.64 ; \mathrm{p}=0.5244)$. No statistical difference was found between levels of education with a p-value of 0.3708 .

Figure 3 describes patient knowledge regarding opioid disposal method, and patients were allowed to choose multiple answers. In this cohort, $47 \%(n=78)$ patients responded that they would take leftover pills to law enforcement or an authorized collector, $16 \%(n=26)$ responded that they would flush the pills down the toilet, $10 \%(n=17)$ responded that they would throw the pills away in a garbage can, and $18 \%(\mathrm{n}=30)$ responded they would use another method that was not listed. One percent $(n=2)$ of patients stated explicitly that they would not dispose of the opioids. No statistical difference was found when looking at individual disposal answers and demographic information (age/gender/current opioid use/race) (all p > 0.05). Overall, 23\% $(n=38)$ said that they did not know how to dispose of opioids. 


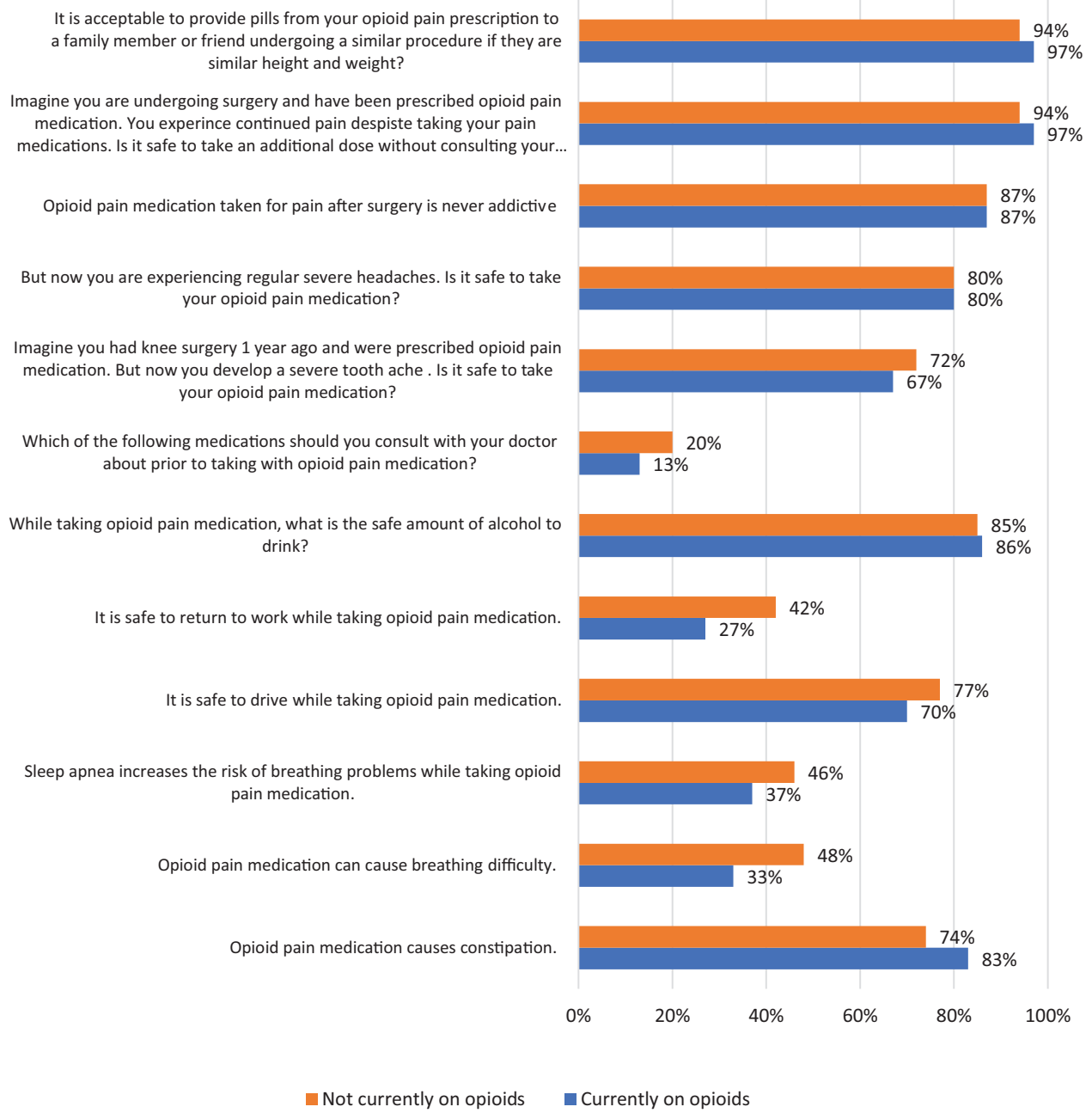

Figure 2. Status of Opioid Usage Versus Question Knowledge

Current opioid users $\mathrm{N}=30$ and patients not currently on opioids $\mathrm{N}=136$.

Table 2. Mean Differences in Overall Knowledge Score

\begin{tabular}{|l|l|c|c|}
\hline & Difference $(\mathbf{9 5} \% \mathrm{CI})$ & F or t value & p-value \\
\hline Current opioid user & & -0.64 & 0.5244 \\
\hline Yes & $-0.30(-1.25,0.64)$ & & \\
\hline No & Reference & & 0.0105 \\
\hline Age & & 3.41 & \\
\hline 18 to 34 & Reference & & \\
\hline 35 to 44 & $-0.32(-1.70,1.07)$ & & \\
\hline 45 to 54 & $-0.84(-2.24,0.56)$ & & \\
\hline
\end{tabular}

(Continued) 
Table 2. (Continued)

\begin{tabular}{|l|l|c|c|}
\hline & Difference $(95 \%$ CI $)$ & F or t value & p-value \\
\hline 55 to 64 & $-1.11(-2.46,0.25)$ & & \\
\hline 65 and older & $-1.92(-3.20,-0.64)$ & & 0.0009 \\
\hline Gender & & 3.37 & \\
\hline Male & Reference & & \\
\hline Female & $1.39(0.54,2.06)$ & & \\
\hline Race & & -2.47 & \\
\hline White & Reference & & \\
\hline Non-white & $-1.37(-2.46,-0.27)$ & & 0.3708 \\
\hline Education & & & \\
\hline Graduate school & $0.45(-0.44,1.35)$ & & \\
\hline 4-year college & $0.62(-0.28,1.51)$ & & \\
\hline$<$ 4-year college & Reference & & \\
\hline
\end{tabular}

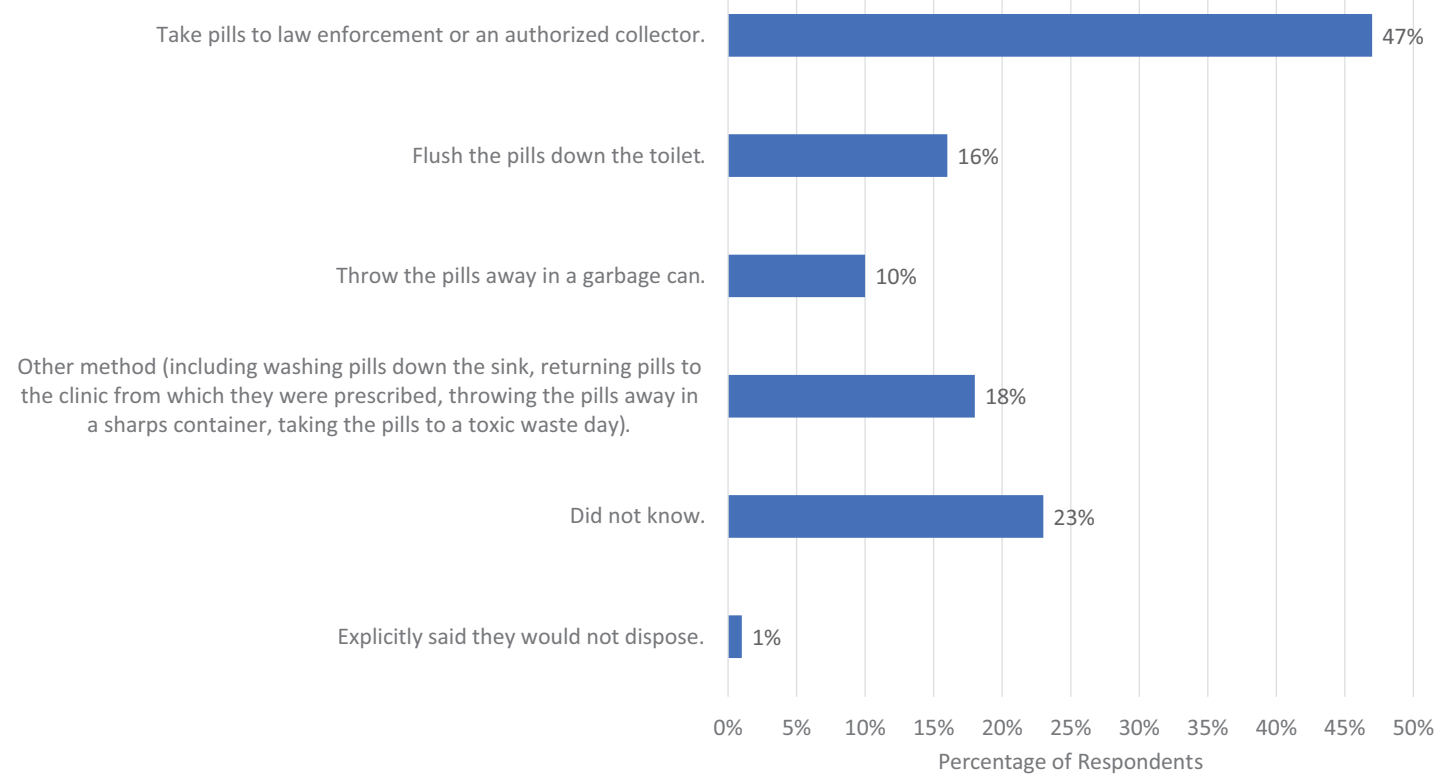

Figure 3. Choice of Disposal Methods

$\mathrm{N}=166$. $\mathrm{Y}$ axis represents the possible choices with the $\mathrm{X}$-axis showing the percentage of patients that reported this answer. 


\section{Discussion}

In this study of adults undergoing elective surgery procedures, we observed comparable opioid knowledge gaps among patients who were currently prescribed opioid medications and patients who were opioid naïve. In addition, we observed knowledge gaps by age, with increasing age associated with decreased knowledge regarding opioids. Our findings suggest the preoperative period is an important opportunity to educate patients regarding the safety and appropriate disposal mechanisms for opioid medications, regardless of prior opioid exposure.

Prior work has studied the effectiveness of educational interventions to improve patients' knowledge of opioid medications. ${ }^{16}$ Our results emphasize the need for such interventions. The POEM survey has been classically used to identify patients that have a lack of opioid use knowledge. ${ }^{3}$ Multiple studies have demonstrated the effectiveness of educational interventions to increase patient knowledge. For example, in the palliative care cancer setting, patients who were given preoperative educational material regarding proper opioid disposal methods were less likely to share medications with others or practice unsafe use of opioids and more likely to be aware of the danger of their opioids when taken by others. ${ }^{10}$ A prior study looked at the effects of using an educational film for patients and found a significant decrease in the pain scores as well as an increase in opioid knowledge among patients that viewed the video. ${ }^{16}$ Our findings provide further evidence that current educational efforts to educate patients at the time of their prescription initiation for perioperative care are inadequate.

Our study has several important limitations. First, our survey was adapted by our study team for the purposes of this study from a prior instrument used to examine prescription opioid behaviors in the setting of opioid education and has not been validated as an accurate predictor of opioid use or knowledge. However, question themes in our survey were taken directly from POEM, which has been used to identify opioid-related knowledge gaps and expectations. ${ }^{3}$ Additionally, our study sample was relatively homogeneous with respect to race and ethnicity, as well as education and income level, and our findings may not be generalizable to other groups. Finally, our study examined patient knowledge in a clinic setting only prior to receiving an opioid prescription for postoperative pain management. Further studies should take place in the postoperative setting to assess changes in patient knowledge after patients fill their prescriptions.

Society and the medical community continue to work to address the opioid epidemic from multiple angles, including implementation of stronger guidelines on prescriptions, education of medical students, and implementation of more education for the patient. ${ }^{4,5,17-22}$ This study indicates the need to increase patient education. Overall, this study demonstrates a lack of knowledge regarding opioid medications in patients about to undergo a surgical procedure. This lack of knowledge is seen in both patients currently on opioids and those that are opioid naive. This evidence points to an opportunity to further educate patients about the risk and proper usage of opioids in the perioperative setting. Studies have shown that an increase in preoperative education changes the knowledge base of the patient in the postoperative setting. Our study also showed that 38 people did not know how to properly dispose of opioids, which indicates a further need to educate patients on proper disposal techniques. By identifying knowledge gaps in surgical patients, our data can serve as a starting point to guide interventions that reduce the incidence of new persistent opioid use following surgery.

\section{Acknowledgments}

None. 


\section{References}

1. Compton WM, Jones CM, Baldwin GT. Relationship between nonmedical prescription-opioid use and heroin use. N Engl J Med.2016;374(2):154-163. doi:10.1056/NEJMra508490

2. Centers for Disease Control and Prevention. Multiple Cause of Death. Wide-Ranging Online Data for Epidemiologic Research. CDC Wonder. 2014.

3. Wallace LS, Wexler RK, Miser WF, McDougle L, Haddox JD. Development and validation of the patient opioid education measure. J Pain Res. 2013;6:663-681. doi:10.2147/JPR.S50715

4. Brummett CM, Waljee JF, Goesling J, et al. New persistent opioid use after minor and major surgical procedures in US adults. JAMA Surg. 2017;152(6):e170504. doi:10.1001/ jamasurg.2017.0504

5. Hill MV, Stucke RS, McMahon ML, Beeman JL, Barth RJ Jr. An educational intervention decreases opioid prescribing after general surgical operations. Ann Surg. 2018;267(3):468-472. doi:10.1097/SLA.0000000000002198

6. Costello M. Prescription opioid analgesics: promoting patient safety with better patient education. Am J Nurs. 2015;115(11):50-56. doi:10.1097/01.NAJ.0000473315.02325.b4

7. Lankenau SE, Teti M, Silva K, Bloom JJ, Harocopos A, Treese M. Initiation into prescription opioid misuse amongst young injection drug users. Int J Drug Policy. 2012;23(1):37-44. doi:10.1016/j.drugpo.2011.05.014

8. Cerdá M, Santaella J, Marshall BDL, Kim JH, Martins SS. Nonmedical prescription opioid use in childhood and early adolescence predicts transitions to heroin use in young adulthood: a national study.J Pediatr. 2015;167(3):605-612.e1-2. doi:10.1016/j.jpeds.2015.04.071

9. Conroy S, Hill D. Failure to identify or effectively manage prescription opioid dependence acted as a gateway to heroin use-buprenorphine/naloxone treatment and recovery in a surgical patient. BMJ Case Rep. 2014;2014:bcr2014207458. doi:10.1136/bcr-2014-207458

10. Dasgupta N, Creppage K, Austin A, Ringwalt C, Sanford C, Proescholdbell SK. Observed transition from opioid analgesic deaths toward heroin. Drug Alcohol Depend. 2014;145:238-241. doi:10.1016/j.drugalcdep.2014.10.005

11. de la Cruz M, Reddy A, Balankari V, et al. The impact of an educational program on patient practices for safe use, storage, and disposal of opioids at a comprehensive cancer center. Oncologist. 2017;22(1):115-121. doi:10.1634/theoncologist.2016-0266

12. Koester MC, Johnson ST, Norcross MF. State-level implementation of health and safety policies to prevent sudden death and catastrophic injuries within secondary school athletics: letter to the editor. Orthop J Sports Med.2018;6(2):2325967117752128. doi:10.1177/2325967117752128

13. Tanabe P, Paice JA, Stancati J, Fleming M. How do emergency department patients store and dispose of opioids after discharge? A pilot study. J Emerg Nurs. 2012;38(3):273-279. doi:10.1016/j.jen.2011.09.023

14. McCarthy DM, Wolf MS, McConnell R, et al. Improving patient knowledge and safe use of opioids: a randomized controlled trial. Acad Emerg Med.2015;22(3):331-339. doi:10.1111/ acem. 12600

15. Camu F. Side effects of opioids in postoperative pain treatment. Acta Anaesthesiol Belg. 1996;47(3):105-109.

16. van Dijk JFM, van Wijck AJM, Kappen TH, Peelen LM, Kalkman CJ, Schuurmans MJ. The effect of a preoperative educational film on patients' postoperative pain in relation to their request for opioids. Pain Manag Nurs. 2015;16(2):137-145. doi:10.1016/j.pmn.2014.05.006

17. Stanek JJ, Renslow MA, Kalliainen LK. The effect of an educational program on opioid prescription patterns in hand surgery: a quality improvement program.J Hand Surg Am. 2015;40(2):341-346. doi:10.1016/j.jhsa.2014.10.054

18. Patry E, Bratberg JP, Buchanan A, Paiva AL, Balestrieri S, Matson KL. Rx for addiction and medication safety: an evaluation of teen education for opioid misuse prevention. Res Social Adm Pharm. 2019;15(8):917-924. doi:10.1016/j.sapharm.2018.007.006 
19. Strand MA, Eukel H, Burck S. Moving opioid misuse prevention upstream: a pilot study of community pharmacists screening for opioid misuse risk. Res Social Adm Pharm. 2019;15(8):1032-1036. doi:10.1016/j.sapharm.2018.07.011

20. Stepan JG, Sacks HA, Lovecchio FC, et al. Opioid prescriber education and guidelines for ambulatory upper-extremity surgery: evaluation of an institutional protocol. J Hand Surg Am. 2019;44(2):129-136. doi:10.1016/j.jhsa.2018.06.014

21. Naqib D, Purvin M, Prasad R, et al. Quality improvement initiative to improve postoperative pain with a clinical pathway and nursing education program. Pain Manag Nurs. 2018;19(5): 447-455. doi:10.1016/j.pmn.2018.06.005

22. McCabe SE, West BT, Boyd CJ. Leftover prescription opioids and nonmedical use among high school seniors: a multi-cohort national study. J Adolesc Health. 2013;52(4):480-485. doi:0.1016/ j.jadohealth.2012.08.007

(C) 2021 Author(s)

This is an open-access article distributed under the terms of the Creative Commons Attribution 4.0 International license, which permits anyone to download, copy, distribute, display, or adapt the text without asking for permission, provided that the creator(s) are given full credit.

ISSN 2470-9727 